\title{
Erratum to: Bacteriophage Polysaccharide Depolymerases and Biomedical Applications
}

\author{
Jianlong Yan $\cdot$ Jinxiao Mao $\cdot$ Jianping Xie
}

Published online: 18 March 2014

(C) Springer International Publishing Switzerland 2014

\section{Erratum to: BioDrugs}

DOI 10.1007/s40259-013-0081-y

A Published-Ahead-of-Print version of this article was made available online on 19 December 2013 at http://link. springer.com/journal/40259/onlineFirst/page/1

The authors have alerted us to the following error:

Page 1, author listing: The list of authors which previously read:

"Jianlong Yan, Jiaoxiao Mao, Jianping Xie"

should read:

"Jianlong Yan, Jinxiao Mao, Jianping Xie"

The online version of the original article can be found under doi:10.1007/s40259-013-0081-y.

J. Yan · J. Mao ·. Xie $(\bowtie)$

Institute of Modern Biopharmaceuticals, State Key Laboratory

Breeding Base of Eco-Environment and Bio-Resource of the

Three Gorges Area, Key Laboratory of Eco-environments in

Three Gorges Reservoir Region, Ministry of Education, School

of Life Sciences, Southwest University, Chongqing 400700,

China

e-mail: georgex@swu.edu.cn; jianpingxie@vip.sina.com

J. Yan

e-mail: 519465867@qq.com

J. Mao

e-mail: 476275984@qq.com 